\title{
Citizen Energy Communities - Insights Into Long- Term Participant Behavior From a Field Study
}

Bent Richter ( $\boldsymbol{\sim}$ bent.richter@kit.edu )

Karlsruhe Institute of Technology

\section{Philipp Staudt}

Karlsruhe Institute of Technology

Christof Weinhardt

Karlsruhe Institute of Technology

\section{Research Article}

Keywords: citizen energy communities, behavior analysis, field study, local trading, consumption shifts, price signals

Posted Date: January 31st, 2022

DOI: https://doi.org/10.21203/rs.3.rs-1299588/v1

License: (c) (1) This work is licensed under a Creative Commons Attribution 4.0 International License. Read Full License 


\title{
Citizen Energy Communities - Insights into long-term participant behavior from a field study
}

\author{
Bent Richter ${ }^{*}$, Philipp Staudt and Christof Weinhardt
}

\footnotetext{
${ }^{*}$ Correspondence:

bent.richter@kit.edu

Institute of Information Systems

and Marketing, Karlsruhe Institute

of Technology (KIT), Karlsruhe,

Germany

Full list of author information is

available at the end of the article
}

\begin{abstract}
Background: Citizen Energy Communities, particularly local energy markets, have been discussed for several years as a concept that allows private households, prosumers, and small local generation facilities to be actively integrated into the existing energy system. According to the literature, it promotes investment incentives and introduces local price signals, to which the participants respond with behavioral changes. However, there is a lack of long-term, real-world data, and insights on participants' behavior in such communities, which is crucial to assess their overall performance and functionality. We fill this research gap by analyzing user behavior based on a one-year pilot project's recorded data and expert interviews with its participants.
\end{abstract}

Results: In three analyses, we observe that participants are initially willing to pay a premium price above the grid tariff for local green power, but this willingness decreases in the long run, affecting investment incentives. In contrast to assumptions in the literature, participants show decreasing activity over time and do not respond to specific information nudges. However, regular reminders and reports are perceived as valuable by the participants and support their integration into the community. Also, we cannot confirm behavioral consumption changes in response to different price signals.

Conclusion: Our results show that the active integration of participants is more challenging than hitherto assumed, and both market mechanism complexity and the need for automation play a central role in a successful design.

Keywords: citizen energy communities; behavior analysis; field study; local trading; consumption shifts; price signals 


\section{Background}

The central challenge for modern energy systems is the transition towards climate neutrality by replacing fossil fuels with renewable energy sources (RES) [1]. However, markets and technology innovations cannot combat climate change alone [2]. This process also requires a social transformation in which the citizens have an essential role [3]. Already today, large amounts of renewable power generation capacity, onshore wind and photovoltaics (PV), are installed decentrally, often in distribution grids, and are owned by private households or small businesses $[4,5]$. These owners represent a new group, called prosumers. In addition, rising environmental awareness has driven increased consumer demand for green, local energy sources and thus sustainable consumption $[6,7]$. With this increasing decentralization in electricity generation and the consistent development towards more local power generation, it requires new concepts to integrate these citizens into the energy sector and raise acceptance for the transition process $[8,9]$. They must be involved and encouraged to play an active role in shaping the energy transition. In recent years, the concept of an energy community where citizens organize themselves locally has gained attention in both research and practice [10]. A distinctive social innovation feature of community energy is the ability to combine the mutual and the public interest [11]. Citizens should be empowered to form local energy communities, becoming so-called 'energy citizens'. The European Union (EU), for instance, supports this development by implementing laws and regulations such as the 'Directive on Common Rules for the Internal Market for Electricity', which promotes the formation of citizen energy communities (CEC) and aims to create a regulatory framework in all member states [12]. The directive defines the CEC as a platform for the cooperation of citizens or local actors with the purpose of providing benefits to its members. It describes a community for exchanging locally generated energy. Different design approaches are proposed in the literature $[13,14]$. One specific CEC design includes a trading platform, frequently conceptualized under the umbrella term 'local energy market' $[15,16]$. On this platform, small local generators and prosumers trade their

surplus with local consumers, including private households or local businesses in the immediate vicinity [17]. The platform utilizes a market mechanism to organize the continuous power and financial flow. In this study, we will refer to this design 
as a CEC because while it represents a special design, the behavioral insights might be transferred to other CEC designs.

According to literature, the CEC concept is well suited to address various energy transition challenges. The platform enables a better integration of local RES because prosumer can directly sell their surplus energy to local consumers and achieve a higher (premium) price than fixed feed-in tariffs or wholesale market prices. These local prices provide investment incentives for additional local renewable expansion [13]. The allocation mechanism introduces local prices, which incentivize participants to contribute to local balancing and, thus, overall grid stability as locally generated energy is consumed on-site [18, 19]. The CEC platform provides the participants detailed information about their consumption behavior and energy origin, improving their environmental awareness and enabling them to behave more environmentally friendly [13]. In addition, these communities represent a novel approach, integrating the emerging group of prosumers into the energy system [20]. However, the actual CEC participants' behavior and the resulting effects on the CEC's performance are largely unknown. Participation is voluntary, and participants are non-professionals. They may have limited experience with the energy sector and are unfamiliar with regular trading on platforms [21, 22]. Consequently, they could misinterpret price signals or information nudges and show unexpected behavior. In addition, they may become overwhelmed with the tasks associated to CECs and leave the community. A first study has investigated the CEC participants' real-world activity but focused mainly on the user's activity and participation drivers [23] and only looked at a shorter time period. However, whether the reported activity levels remain equally high in the long run is unclear. CEC participants' long-term, real-world behavior, and its effect on associated indicators (premium prices for local sources, bid adjustments, and consumption shifts) are unknown and require additional research.

Against this backdrop and to approach this research gap, we assess the market design of an implemented CEC field project. The project includes two different local energy sources: PV and combined heat and power (CHP). By analyzing the data recorded over the one-year project duration, we investigate if the market design can incentivize participants to shift their consumption significantly, whether they are 
willing to pay premium prices for local renewable energy in the long run, and we evaluate the overall activity of the participants. In order to draw a comprehensive picture of the participants' behavior, we further enrich the results drawn from the quantitative data analysis with insights from conducted qualitative interviews. We summarize our research endeavor, raising the following research questions: What long-term behavior of participants can be observed in CECs regarding i) the willingness to pay for local energy sources, ii) the overall activity and responses to information nudges, and iii) the reaction to price signals in regards to consumption shifts?

The quantitative and qualitative analyses of the project data and the participants' interviews represent the first longitudinal insight into participants' behavior from a CEC field project. We approach our research questions by means of three analyses. The first analysis focuses on the participants' preferences for the different local energy sources. We analyze the submitted bid prices to determine which of the two local sources (PV or CHP) the participants prefer and assess their willingness to pay for these power sources. The second analysis investigates the participants' platform activity because the CEC platform adds less value if participants lose interest over time and become inactive. We analyze the bidding behavior, how participants react to different information nudges, and evaluate the participants' interview statements to assess the overall activity on the platform. Since local grid balancing is a central value proposition of the CEC concept, the last analysis investigates the effectiveness of price signals, which should incentivize participants to shift their consumption to times with lower prices. We examine the participants' consumption behavior for different price signals. Based on interview statements, we also evaluate how participants who become a prosumer adapt their consumption behavior.

This work is structured as follows. In Chapter 2, we describe different CEC definitions, provide a conceptional overview of different approaches, and describe realworld results from the literature. We provide a detailed description of the examined project and its infrastructure in Chapter 3. In Chapter 4, we perform the three analyses to investigate the participants' behavior and how it changes throughout the project. We discuss our observations in Chapter 5 and indicate potential future research based on our results. Finally, Chapter 6 concludes our findings. 


\section{Related Work}

Before the introduction of the regulatory framework and term 'citizen energy community' by the EU, researchers have already discussed various concepts to integrate citizens into the energy sector, actively [24]. The fundamental principle is that participants form a community and share electricity with each other. The idea has been explained for several years, mostly under different names including 'local energy community' [25], 'renewable energy community' [26], 'sustainable energy community' [27], 'renewable energy cooperative' [28], 'citizen energy cooperative' [29], or 'community microgrid' [30]. The authors of [31] explore the variety of interpretations and define two core areas that describe these concepts. First, communities must provide a high level of participation for the respective participants. Second, the community outcomes and benefits must be distributed to its participants.

All the above-mentioned terms focus on connecting citizens in communities and providing benefits for its participants, but with different characteristics and priorities. [32] investigates different community concepts that exclusively focus on financing renewable power plants without any local energy exchange. He distinguishes between different forms, for example, investing in commercial power plants or joint financing of own facilities that are not used for self-supply. The author refers to these concepts as energy cooperatives. [32] separates these concepts from the energy community concept with a local exchange of energy. The described concept of renewable energy cooperative [28] and citizen energy cooperative [29] also fall under this definition.

Another special form is the concept of the 'community microgrid', which is also often used in the context of energy communities. [30] define community microgrids as a group of interconnected loads and energy sources that act as a single entity to the grid. [33] describe the concept as a community, in which all members are connected to the same local bus through which they exchange energy with the public grid or among themselves. [34] describe community microgrids as self-contained systems that may be connected to a central grid or function on their own. Within the microgrid, all connection points (e.g., households, small businesses, prosumers) are part of the community. Therefore, community microgrid concepts focus on the physical connection of participants and represent a special form of energy communities. In contrast to the other concepts, it differs in its openness to participation 
with its grid-based restriction. Participation in other energy communities concepts is voluntary and not necessarily tied to the grid topology [35].

The concepts and descriptions of 'energy cooperatives' and 'community microgrid' can be differentiated from the energy community concept because their focus is exclusively on monetary benefits, or participation within them is not voluntary. Other terms meet the two criteria of [31]. [25] uses the term 'local energy community' to describe a set of residential and industrial actors connected to the same distribution network to form a community voluntarily. [27] refer to the concept as 'sustainable energy community'. They emphasize the collective, sustainable use of own generation facilities and expand the local exchange characteristic to other sectors such as heat or water. The authors argue that the goal of sustainability also includes additional commodities besides energy. [36] coin the term 'collective and politically motivated renewable energy project' (CPE). The authors emphasize that an energy community must have a political purpose, and participation should generate benefits for each member. In addition, [37] provide a typology that distinguishes between centralized, distributed, and decentralized communities and defines them as a social structure fostering a sustainable energy supply. They also extend the community focus to other commodities like heat, transportation, water, or waste management, similar to [27]. Overall, the concept can be characterized as an approach in which citizens voluntarily join together in communities to exchange locally generated energy and thus generate added value that is not necessarily monetary.

The European Union has introduced the legal concept of the CEC to group all these different terms and descriptions and provide a regulatory framework [12]. The 'Directive on Common Rules for the Internal Market for Electricity' defines the CEC as a legal entity that is based on voluntary and open participation and is effectively controlled by members or shareholders. These can be natural persons, local authorities, municipalities, or small enterprises. Its primary purpose is to provide environmental, economic, or social community benefits to its members or shareholders or to the local areas where it operates, rather than to generate financial profits, exclusively. The concept engages in the generation, distribution, supply, consumption of energy. CECs are platforms to actively integrate citizens into the energy system on a local level, empower the energy sector's decarbonization [38], and substantially benefit the local value chain and energy system [39, 40]. 
[40] analyses several European community projects, their goals, and experiences. The authors point out that these communities support the energy transition, foster citizens' participation in renewable energy, and integrate prosumers as well as consumers. They thus allow consumers access to capital and benefits of decentralization independently of their income. Several CEC concepts utilize various digital technologies and a trading platform to enable their stakeholders to interact with each other and exchange energy. On these platforms, an allocation mechanism distributes the available energy. In the literature, different mechanism designs, and corresponding benefits are discussed [41]. Many of them are based on underlying assumptions about the participants' behavior or preferences. As mentioned in the previous chapter, we focus on three crucial assumptions about CEC participants: heterogeneous willingness to pay for local energy sources, overall platform activity behavior, and responses to price signals.

A central assumption in the literature is that CEC participants have a heterogeneous willingness to pay for different energy sources and pay premium prices for renewable or local energy sources. [35] assume that CEC participants have heterogeneous goals and a corresponding willingness to pay. They differentiate between two prosumers types, a profit-orientated prosumer with a low willingness-to-pay and environmentally concerned prosumers with a high willingness-to-pay. The authors develop a trading mechanism concerning the individual willingness to pay. They create a sample community with a set of arbitrary participants (ten private households and five small businesses), and assume different willingness-to-pay values for each participant. Similarly, [42] proposes an auction-based approach to satisfy community participants' preferences, allowing them to pay premium prices and increasing community self-sufficiency. The authors state that current approaches do not consider heterogeneous user preferences. They propose seven clearing mechanisms and evaluate their performance with the help of a Monte Carlo simulation. The assumption of a different willingness to pay for different energy sources is not fundamentally wrong, as the meta-regression analysis of several studies by [43] and a choice experiment by [44] indicate. Leveraging evidence from a choice-based experiment, [45] identified a subgroup of potential community participants, who state they would pay premium prices for local energy. However, it remains unclear if the 
participants' indicated willingness to pay premium prices can be observed within a real CEC. Also, it is unknown how the platform influences the participants' behavior and willingness to pay over time.

Most studies assume a regular activity of participants in CECs. [46] analyze bidding strategies given different market mechanisms. The authors simulate the behaviour of two different participants with a multi-agent simulation. They differentiate between zero-intelligent and intelligent behavior. The former is displayed by random bidding, and the latter is based on a reinforcement learning algorithm. The authors show that intelligent behavior by agents leads to better market results. However, they assume a regular interaction by the participants and do not incorporate behavioral restrictions, for instance, no activity at night because a human participant would sleep in these periods. Similarly, [47] model participant behavior with the help of a deep reinforcement learning approach. The authors utilize the resulting trading strategies to evaluate and comprehend potential participant behavior. The study investigates a sample community based on different data sources but without benchmark trading data from field projects. Also, the authors do not incorporate possible human restrictions, which also influence trading ability. [23] provide first field insights into CEC participants' behavior. The corresponding project ran for a total of four months, and the authors showed large differences in the activity of participants. The authors cluster participants' behavior into three groups based on their activity. About $35 \%$ are active but with low engagement and prefer bidding automation, $30 \%$ are active but prefer a manual input, and the remaining $35 \%$ are inactive participants. However, the authors do not discuss how participation activity can be influenced and if the behavior changes in the long run as the project ended after the four months period.

The third assumption is that local price signals can influence the participants' consumption behavior and contribute to system balancing. [17] state that CECs can provide investment incentives and support local grid balancing. However, the authors do not provide any empirical evidence. [48] design an energy exchange platform and simulate trading on it. They show that local trading within a community supports balancing local demand and supply. However, their results are based on the assumption that participants are willing to shift their consumption. [49] confirm in their meta-study that consumers reduce their peak load in response to higher peak 
prices. They also state that this effect gets more potent with enabling technology such as in-home displays, which present the load data and prices. In the study by [23], the authors report indications for an increased load-shifting by the participants in their field project. However, these statements are based on interviews and not quantitative data analysis. Therefore, it remains a research gap if local price signals in CECs lead to consumption shifts by the participants.

Summarizing, previous studies investigate the effects of different CEC platform designs and their performance by applying simulations. These simulations are a valid method to test and investigate different concepts. However, authors need to make assumptions regarding the different participant groups, their utility functions, and strategies. The CEC concept includes inexperienced users like private households and prosumers. It is unknown how these (often) non-professionals behave in this new environment, what goals they pursue, and how they interact on the platform. With this uncertainty, longitudinal field studies are essential to provide valid information for the academic discourse and platform designers. We close this research gap in this study by evaluating a CEC implementation over the period of one year regarding the three core assumptions introduced above and obtain valuable insights into the real-world behavior that can be expected of CEC participants.

\section{Project Description}

In this study, we investigate the participant behavior from the field project, the Landau Microgrid Project (LAMP). The project is localized in a small neighborhood with only private households. The project team chose this location because the neighborhood lies within a small distribution grid and project's grid falls under special regulations. National legislation often prohibits the sales of self-generated electricity by prosumers directly to their neighbors. However, within this regulatory niche, this does not apply, which is further enforced through the European legislation on CECs. Due to the preferential treatment of prosumers in this regulatory niche, it is possible to establish economically beneficial local electricity trading. The grid has only one connection point to the public distribution grid and is owned by the project's utility partner. A $50 \mathrm{~kW}$ CHP plant is installed for heat supply in addition to a $23 \mathrm{kWp}$ PV system. In addition, three participants installed a PV system during the duration of the project and became prosumers. The three pro- 
sumers feed their surplus generation into the grid. The five power generation units are the only available local power sources. Differences between local demand and the available local supply are balanced through the interconnection point to the public grid. In total, there are 118 connection points (households) in multifamily and single-family houses in the project's grid. At the beginning of the project, the project was advertised in the neighborhood, and 11 households decided to participate. Of these, five live in single-family homes, and the rest lives in multifamily homes. The household size is between one and five persons. The average age of the participants is 49 .

\subsection{Platform infrastructure}

A CEC application was developed for the project to serve as a platform for the coordination. The platform and its information system are the CEC's necessary infrastructure. The platform manages the data and information flows, important for the functionality, and enables coordination between the local power generation and consumption. The platform is composed of four modules: database, smart meter hardware, user application, and the coordination mechanism. The database is the central module where all generated or recorded data is stored and retrieved. The smart meter hardware describes the metering infrastructure that is installed at each participant's grid connection point. It records the households' load values and transfers the data to the database in regular intervals. The participants have access to their consumption data, market prices, and generation quantities via a mobile user application. In addition, there is a web interface that participants could use. Besides viewing individual information, participants can also set their bid prices via the user application. In addition to the user application, the project team sent individual reports via email to each participant weekly. These reports included the aggregated consumption and market data of the previous week. The last module of the platform is the market mechanism. Since the project distinguishes between different energy sources, the mechanism consists of two separate but intertwined markets: a local market for PV energy and one for energy from the CHP. Both markets are structured as a double-call auction with sealed bids and have a uniform pricing mechanism. The operation of the mechanism is identical in both markets. First, the bids from the supply side are sorted in ascending order based on the 
bid price, and those from the demand side are sorted in descending order. Then the bids are matched accordingly until the bid price of the supply bid exceeds the demand bid price. The market price is then equal to the last bid price. At the beginning of the project, the market price equaled the bid price of the supply side. Later the mechanism was changed, and the market price corresponded to the last successful bid price of the demand bids to assess whether this had any impact on the bidding activity. Participants might obtain all of their demand from only one of the two markets (PV and CHP) depending on the bid prices and available quantities. Therefore, it is necessary to execute the markets consecutively. The market for which the majority of participants have placed higher bids is executed first. A detailed description of the mechanism is given in [50]. If a participant is already supplied on the first market, the bid on the second market is no longer considered. The public grid subsequently serves all bids that the local market could not serve. This backup ensures the security of supply. For these transactions, the local utility standard grid tariff of 23.7 EURct/kWh applies. Comparably, every locally generated kilowatt-hour that cannot be consumed locally is sold to the public grid at the corresponding feed-in tariff (11.0 EURct/kWh for PV electricity and 8.0 EUR/ct for CHP). All transactions are recorded by the information system and stored in the database. A complete overview of the platform architecture, its processes, and utilized technologies is given in [51]. The interval of the market-clearing is 15 minutes. However, participants do not have to place a bid every 15 minutes, actively. Instead, the bid price they set is valid for all coming intervals until they change it. The bid quantities correspond to the generation and consumption values recorded by the smart meter hardware. As mentioned before, three of the eleven households invested in PV systems during the project duration. These three participants thus became prosumers, generating their electricity and, at times, supplying surplus energy to the local grid. If the amount of energy generated is insufficient, then the prosumer continues to consume energy from the grid.

\subsection{Trading phase description}

Throughout the project, different trading phases were executed during which different focus questions were addressed. Over the first four trading phases A to D, the amount of information in the weekly report was steadily increased from phase 


\begin{tabular}{|c|c|c|c|c|}
\hline Phase ID & Phase Name & Description & Duration & $\begin{array}{l}\text { Report Interval } \\
\text { (per Week) }\end{array}$ \\
\hline C & Household Appliances Load & B + List with average load values of typical household appliances & $\begin{array}{l}16.10 .2019 \\
04.02 .2020\end{array}$ & 1 \\
\hline D & Community Consumption Costs & $\mathrm{B}+$ Average energy cost of all community members & $\begin{array}{l}05.02 .2020 \\
31.03 .2020\end{array}$ & 1 \\
\hline $\mathrm{F}$ & Intraday Low-Price Period & $\mathrm{D}+$ Daily PV market price drop between $10 \mathrm{a} \cdot \mathrm{m}$ and $2 \mathrm{p} . \mathrm{m}$ & $\begin{array}{l}01.05 .2020 \\
31.05 .2020\end{array}$ & 2 \\
\hline G & Low-Price Day & $\mathrm{D}+$ Announcement of one low PV market price day in each period & $\begin{array}{l}01.06 .2020 \\
30.06 .2020\end{array}$ & 2 \\
\hline $\mathrm{H}$ & Dynamic Market Prices & $\mathrm{D}+$ Change in the mechanism such that demand bids set the market price & $\begin{array}{l}01.07 .2020 \\
05.08 .2020\end{array}$ & 2 \\
\hline
\end{tabular}

Table 1 Trading Phases 
to phase. This information increase allows us to assess how participants react to different types of information with their bids and consumption. Only information on the total weekly consumption and the individual absolute and average costs was provided in phase A. In the second phase, the individual energy mix (PV, CHP, Grid) was included. In phase $\mathrm{C}$, a list of household appliances and their average consumption was added to the report. This phase was included based on feedback from participants who stated that they were not aware of the consumption of different devices in relation to other appliances in the household. In phase $\mathrm{D}$, the report included the overall average costs per $\mathrm{kWh}$ across all participants to allow a comparison of the individual performance in regard to the group. Each of these reports was sent out once per week. In trading phases $\mathrm{E}$ to $\mathrm{H}$, deliberate price signals were placed in order to examine their effects on participants. These treatments aim to investigate whether participants react to such signals with a bid price change or load shift (e. g., shifting loads within the day or between days). During these phases, the report frequency was increased to twice per week. Each report in phase E announced a fixed PV market price for the subsequent days until the following report. This temporal fixed market price changed with each report and corresponded to the lowest price of all successful bids since the last report. Thus, the participants could indirectly influence the upcoming market price by changing their bid price. In phase $\mathrm{F}$, the PV market prices were shifted between two values. Each day from 10 a.m. to 2 p.m., the PV market price was reduced to the level of the feed-in tariff of 11.0 EURct/kWh. At any other time, the price was set to 20.0 EURct $/ \mathrm{kWh}$. In the following phase $\mathrm{G}$, the market price on the PV market was reduced to 11.0 EURct/kWh on one day between two reports and 20.0 EURct/kWh on all other days. The day with the longest sunshine hours was selected and announced based on weather forecasts for the lower price. In trading phase $\mathrm{H}$, the market mechanism was changed so that the demand side determined the market price by the bid price of the last successful demand-side bid. The reasoning behind this phase is to investigate the effect of a strong market price dynamization and to analyze how participants react if their bid changes are more directly reflected in the market results. In the final trading phase I, participants were provided with additional information on their performance. For this purpose, we calculated and communicated potential 
savings retrospectively for each participant, given that their market behavior would have been optimal.

\section{Method}

As described in the previous chapter, eleven participants took part in the project, eight as consumers (participants 1-4,6,8,10,11) and three as prosumers (participants $5,7,9)$. The small sample makes it hard to deduct statistically significant results, which is a particular problem in field studies. Additionally, there is no experimental control group, and other external effects are present in this project, such as the selection bias or unobserved influences on behavior [52]. Therefore, we follow the suggestion of [52] and use a mixed-method approach for the evaluation by analyzing the data and behavior quantitatively and, additionally, perform semi-structured interviews with the participants to assess and validate the observed data. The quantitative approach is focused on identifying interesting behavior apparent in the data and on drawing possible conclusions. The qualitative analysis helps us in interpreting the observed phenomena from the quantitative analysis and provides further insights into the background of the participant behavior. It also aims at identifying possible weaknesses in the project design or additional potential.

The available project data includes load data of the participants, power generation data, the bid prices entered via the user application, as well as the transactions and market prices determined by the market mechanism. The processed data is examined for anomalies and analyzed with regard to the three research questions. We conducted semi-structured expert interviews according to [53] at the end of the project for the qualitative analysis. The interviews follow a guideline that allows the interviewers to ask questions on different topics and switch between the guideline topics based on the answers. The interviews are conducted via telephone, recorded, and transcribed. Before each interview, the interviewer explained the goal of the interview and provided some contextual information about the interview guide. The interviewees were informed about their data protection rights and gave their consent to record the interview. The quantitative study is divided into three thematic areas: the analysis of participants' preferences, the analysis of the bidding strategy in the trading phases and the analysis of consumption reactions to price signals. At the same time, we distinguish between consumers and prosumers for each of these 
three analyses. The first analysis examines the relative relationship between each participant's two bid prices (PV \& CHP), in detail. Furthermore, we asked how the preference between the two power sources changed throughout the project's duration. Finally, we assess the potential of maintaining premium prices for local generation. Building on this, we examine the participants' overall activity and their bidding strategies in relation to the different information in the reports. Finally, we analyze the participants' consumption behavior in detail and their reaction to different price signals. In addition to the quantitative analysis, we add interview statements from the participants to better understand specific observed behavior.

\section{Results}

\subsection{Evaluation of participant bids - preferences and bidding behavior}

The first analysis focuses on the participants' bid prices for the two local sources (PV \& CHP), and we differentiate between consumer and prosumer participants. First, we analyze the bid prices and their change over time. We state our first hypothesis (H1.1) that participants have different preferences for local sources. Second, we evaluate whether participants are willing to pay premium prices for local energy sources. We define a premium price as a bid price above the known reference price for energy from the public grid that is also displayed prominently in the user application. The second hypothesis (H1.2) states that participants are willing to pay premium prices.

Figure 1 Consumer PV bid prices throughout project duration

Figure 2 Consumer CHP bid prices throughout project duration

Consumers: The Figures 1 and 2 gives an overview of the consumer participants' bidding behavior within the project over the entire duration. In the beginning, all but two participant exhibits a higher preference for electricity from the local PV system than the local CHP. Only participant 10 sets the same bid prices for both sources, with 21.0 EURct/kWh. The mean value of all initial PV price bids is 25.1 EURct/kWh, while the mean value of all initial CHP bid prices is 19.7 
EURct/kWh. Therefore, at the start of the project, the consumers show a higher preference for local PV power than for power from the CHP and confirmed our hypothesize that participants differentiate between local sources. However, we observe a negative trend in the adjustment of bid prices throughout the project. In the end, the average bid price for PV electricity is 20.1 EURct/kWh, which is 5.0 EURct/kWh lower than at the beginning of the project, and, more importantly, it is lower than the reference price. The lowest PV bid was submitted by participant 1 with 12.0 EURct / kWh. This participant also exhibits the highest reduction from the initial 29.0 EURct/kWh bid to 12.0 EURct/kWh. The dynamic is similar for CHP bid prices but less pronounced. On average, the bid prices decreased by 2.6 EURct /kWh from 19.7 EURct/kWh to 17.1 EUR/kWh. Again, participant 1 shows the highest reduction from 22.0 EURct $/ \mathrm{kWh}$ to $15.0 \mathrm{ct} / \mathrm{kWh}$. Therefore, we conclude that while participants make a difference between local energy sources, differences slightly lose meaning over time. This result confirms our first hypothesis (H1.1). We observe a higher preference for the local PV generation than the CHP generation, but the price gap between both sources decreases from 5.3 EURct/kWh to 3.0 EURct/kWh. Most participants, throughout the project, hold this order of preference, and there are only isolated temporary deviations from this order by individual participants. In addition, we conclude from the decreasing bidding price trend that the willingness to pay for local sources seems to diminish throughout the project. One explanation for this could be the market itself. Long-term, repeated markets interactions undermine the participants' moral values and intentions [54]. For example, participant 1 first lowers the bid prices for both sources and then increases them again shortly after, but on a lower level. It seems that the participant tried to influence his individual values. The interview confirmed that he tested the market mechanism for a better understanding and cost reduction. This observation supports the previously mentioned invalidating effect of the market on individual intentions.

This negative trend also impacts the premium prices participants are willing to pay for local electricity. The initial bids show that some consumers were willing to pay a premium for local, green electricity. Five of the eight consumers set a higher bid price than the stated reference price (grid tariff) of 23.7 EURct/kWh, which was 
communicated to participants and displayed in the user application. Participant 11 has the highest initial bid price of 30.0 EURct/kWh. Of the remaining three consumers (participants 4,6,10), who bid below the reference price, participant 10's bid price was the lowest with 21.0 EURct/kWh. In contrast, all initial CHP bid prices were below the reference price. Here, participant 10 submitted the highest bid with 21.0 EURct/kWh, and participant 11 the lowest with 16.0 EURct/kWh. Thus, the analysis shows that initially, some participants were willing to pay a premium for PV generation while no participant bid a premium price for local CHP energy. Therefore, the observation of the initial bids seems to confirm literature indications like the survey of [45]. The authors identify in their survey that premium prices only apply to a subgroup of potential participants. However, throughout the project, the above-mentioned negative trend leads to only two participants that still submit PV bid prices higher than the reference price, as shown in Figure 1. The average PV bid price decreases below the reference price of 23.7 EURct/kWh. Only two out of eleven participants retained a higher bid price than the reference price at the end of the project, and one of these never changed his bid price and thus never actively interacted with the market. Based on our observations, we can conclude that the initial high willingness to pay premium prices for local green energy diminishes over time. Therefore, we have to reject our hypothesis regarding premium prices (H1.2). These results challenge the previously mentioned research result by [45]. The identified subgroup seems to be smaller than the current research assumes because participants initially show the willingness to pay premium prices but do not uphold this willingness over a longer period. Even though premium prices cannot be maintained, all submitted bid prices are above the feed-in tariff. Therefore, local generators can still achieve a higher selling price within the regulatory niche where specific levies are not paid. Thus, there is still an incentive to expand renewable generation capacity within the CEC but less pronounced.

Figure 3 Prosumer bid prices throughout project duration

Prosumers: The analysis of the prosumers' bidding behavior shows a similar picture compared to the consumers. In addition to the possibility of buying local electricity, these actors can also sell their PV surplus. Therefore, they also have a PV 
selling bid price. As mentioned above, there are only three prosumers in total in the project (participants $5,7,9$ ). The observation period for the prosumers is limited to five months from April to September due to the need for technical adjustments to the platform infrastructure caused by the installation of the PV panels. Figure 3 shows all submitted bid prices by the prosumers. Different from the consumers, all three prosumers start and remain with buying bid prices below the reference price. However, note that prosumers had previously participated as consumers and therefore might have already adjusted their bid prices. We can confirm the negative trend from the previous consumer analysis, but it is less pronounced. The average PV buying bid price starts with 16.7 EURct/kWh and decreases to 15.7 EURct/kWh. Similarly, the average CHP buying bid price decreases from 18.0 EURct/kWh to 15.7 EURct/kWh. Again, the bid price gap between PV and CHP also reduced for prosumers over time. Interestingly, prosumers seem to favor local power from the CHP system over power from the PV system, which is different behavior in comparison to the consumers. A reason for this could be the fact that they generate energy by themselves. However, due to the small sample size, we cannot rule out a selection bias or other external effects. Nevertheless, prosumer initially differentiate between local energy sources (H1.1). Since all buying bid prices are below the reference price, we also reject the premium price hypothesis (H1.2) for prosumers. Prosumers are not willing to pay premiums on prices for local, green energy. In addition, the PV selling prices are lower or equal to the buy bid for local PV power. This observation confirms that prosumers understood the underlying market mechanism and are willing to sell their surplus energy at lower prices than consumers (and themselves) would buy it.

Summary: The first analysis shows that local PV sources are seemingly preferred by consumers over local CHP, and some set market prices at a premium above the reference price, especially at the beginning of the project. Both groups show a negative trend regarding their bidding prices over time, which might be rooted in the repeated interaction with the market mechanism. All but two of the participants were unwilling to pay a premium for local, green electricity over the project duration. Therefore, it should not generally be assumed that there is a willingness to pay premiums on local, green electricity and that the initial willingness does not persist in the long term. 


\subsection{Evaluation of bidding behavior - response to price and information signals}

The second analysis focuses on the participants' activity and reactions to different information and market price changes. First, we examine the bidding activity in detail and assess the underlying rationales through the interviews. Regular activity is a key success factor for CECs as continuous behavior adaption helps to balance the grid, and it is often implicitly assumed in the literature. Therefore, the first hypothesis of this analysis is that participants interact with the market platform on a regular basis (H2.1). Second, we evaluate the participants' reactions to different information nudges in the regular reports. The reports are intended to support the participants in evaluating their bidding strategy, besides the available information via the user application. As described in Chapter 3, the reports differ in each trading phase and contain aggregated individual information from the previous days. The second hypothesis of this analysis is that the individual information in the reports encourages participants to evaluate their bidding strategy and to adjust their bids (H2.2). For this analysis, we evaluate the trading periods A-E, H, and I. We exclude phases $\mathrm{F}$ and $\mathrm{G}$ because those trading phases focus on incentivizing consumption shifts with price signals, which are the focus in the third analysis.

Consumers: The bidding behavior analysis reveals that the participants do not exhibit extensive bidding activity. As Figure 1 shows, the maximum number of individual adjustments is 12 for the participants 1 and 2 over the entire year. In contrast, participants 4 and 8 have not adjusted their bid prices once. Participant 3 made three adjustments. Participants 6 and 11 changed their bids four times, and participant 10 eight times. We observe four consumer bid adjustments per month on average, which indicates a low bidding activity. This observation shows that consumers rarely acted on the platform in terms of bid adjustments. However, this does not mean that participants were consistently inactive. We conclude from the interview statements that participants mainly used the regular reports to check individual data and to follow the project progress. We identify two main reasons for the low activity: the perceived market complexity linked to insufficient market feedback and participants' available time. Some participants stated that they were reluctant to actively adjust bid prices, as it was not always clear what effect this might have. Participants 6 and 11 state that they perceived the market mecha- 
nism as too complex and did not understand the possible outcomes of bid price changes. This uncertainty resulted in the low number of bid adjustments by these two participants. In contrast, participants 1 and 2 stated that they have become more familiar with the market by testing it and had dealt more intensively with it. Participant 11 indicated that he had only limited time resources, and the results from the weekly reports were satisfactory, so there was no need for action. Participant 6 monitored her consumption data with the help of the reports but was hesitant to act. Participant 8 justified his inactivity, saying that the financial saving potential on the market is too small. In addition, some participants stated that they often forgot the project until they received a new report. Participant 4 indicated that the functionality of the reports and the app to monitor individual load data and costs was sufficient, and there was no need for bid adjustments from his perspective. He also mentions a lack of time. The available time seems to be a crucial factor for the participants. Participants 8 and 11 explicitly stated that they did not want to use their limited time to understand the market mechanism in more detail. Overall, we partly reject the first hypothesis of this analysis (H2.1). Consumers show a low bidding activity due to the perceived market complexity and available time. However, they monitor their data with the help of regular reports. Therefore, the participants show interest in the community but are less active than the literature assumes.

According to the statements of individual participants, the regular reports were helpful to follow the project and interact with it. This insight is also visible in the data analysis. Despite the general low frequency of bid submissions, about $50 \%$ of the bid adjustments by participants 1, 10, and 11 occur within a 24-hour window after receiving a report. For participants 2 and 3, this share is $33 \%$, and $25 \%$ for participant 6 . It seems that reports enable the participants to evaluate their bidding strategy better and trigger interactions. In a more detailed analysis, we investigate the bidding responses to the different trading phases and their information nudges to assess their effectiveness. In the first two trading phases, where the reports include consumption costs (A) and consumption costs + the energy mix (B), there is no bid price adjustment at all. This suggests that either the information provided in both phases did not cause the participants to change their preferences, or the 
information did not offer any added value for them to derive a corresponding action from it. In contrast to the first two phases, we identify two clusters of increased activity in the following trading phases $\mathrm{C}$ and $\mathrm{D}$. In phase $\mathrm{C}$, the report includes the information of the previous phase (B) and additional information about the average consumption of household appliances. At the beginning of this phase, we identify twelve bid price adjustments by the participants 1,6 , and 10 , seven directly after a report and two (participant 1) shortly before a report. Later in this phase, there is only one interaction of participant 6 . In phase $\mathrm{D}$, the participants receive, in addition to the information of trading phase B (individual costs and energy mix), the community average consumption costs for locally consumed energy (both PV and CHP). In the beginning of this phase, we cannot observe any bidding activity. However, on the day of the fourth report mailing (5th March), participants 2 and 11 adjusted their bids. In the subsequent period of this day, we identify a higher bidding activity. In addition to participants 2 and 11, participants 1, 3, 6, and 10 also adjusted their bid prices. Overall, we identify bidding activity in trading phases $\mathrm{C}$ and $\mathrm{D}$, which is connected to the report sending. However, it is unclear if the provided information nudges triggered a reaction or other external events.

In contrast to the previous trading phases, phase $\mathrm{E}$ does not provide any additional information but allows consumers to influence the PV market price actively. The PV market price was determined and fixed between two report periods. Its value was then equal to the lowest successful consumer bid price since the last report. During this phase, only participants 1 and 2 adjusted their bids. Both participants adjust their bid prices seven times in total, two times directly after a report, four times shortly before a report mailing, and only once without any connection to a report. Especially, the four adjustments before the report suggest that the participant specifically tried to change the market price actively. Participants 1 and 2 report in the interview that they tried different bid prices to better understand the market mechanism. However, only these two participants react to the incentive in this phase. Therefore, we conclude that the temporarily fixed market prices and the ability to influence them can trigger engagement but addresses only a small group of participants. The recorded behavior also supports this conclusion in trading phase $\mathrm{H}$. In this trading phase, the market mechanism was changed in a way 
that the lowest successful demand-side bid price continuously set the market price. However, a reaction in phase $\mathrm{H}$ is only recorded from participant 11, directly after sending a report, and no other participant showed any bidding activity. Therefore, we conclude from phases $\mathrm{E}$ and $\mathrm{H}$ that influenceable dynamic market price changes do not trigger bidding activity. This might indicate that customers prefer an external pricing mechanism. In phase I, which includes information about the optimal bidding behavior, no activity was recorded. The interview statements support these observations. Participants state that they primarily monitored their individual data and performance via the reports and only interacted with the market if they felt that something went wrong. The overall data shows that the participants become more inactive with increasing project progress. This is not a surprising finding, as the novelty effect wears out [55]. However, this finding is still important to note for engineers of CECs.

Overall, we observe decreasing activity and interaction with the CEC over time. Participants generally show a low bidding activity and rarely react to information nudges or market price changes by adjusting their bid prices. We therefore reject the first hypothesis of this analysis (H2.1). However, participants state in the interviews that they use the reports to monitor their performance and follow the project. In addition, regular reports seem to have an impact on the participants' overall activity level. A certain proportion of the low number of bid price adjustments are in the period after the report mailing, showing that they can encourage a reaction. The deeper analysis reveals that information like average consumption information of household appliances and community average consumption costs trigger participant's bidding activity. Also, the ability to influence the market price seems to be interesting for some participants. Nevertheless, inactivity increases with the project progress, and we conclude that the reports in general but not specific information nudges act as reminders to encourage participants to re-engage with the CEC. Therefore, we partly confirm the second hypothesis (H2.2).

Prosumers: The prosumers show an increased bidding activity compared to the consumers. We recorded six bid adjustments per month on average. Nevertheless, even this higher activity is comparably low relative to the length of the observed period. In the interview statements, the prosumers mention the lack of time and 
market complexity as central obstacles to become more active, similarly to the consumers. Participant 9 stated that he followed the project via the reports but was often too lazy to adjust the bids. He also explained his low activity level by the perceived time-benefit ratio. He confirms our observation from the consumers that time is a limiting factor for the participants. Also, participant 5 suggested changing the market mechanism to a mechanism with more direct feedback, for example, individual market prices. Participant 9 suggested more automation and less complexity. The analysis of the report's responses reveals that all bid adjustments occurred within 24 hours of the report being mailed. This suggests that the prosumers react more strongly to external triggers and rarely become active by themselves. However, the small sample is again a limiting factor. No specific trading phase results in higher bidding activity. Each prosumer has an active period. Participant 5 shows the most bidding activity in the first two months of participating as a prosumer during trading phases E and F. Participant 7 was more active in trading phases G and $\mathrm{H}$, and participant 9 only showed some activity in the last period I. Overall, the regular reports in general and no specific information nudges seem to support bidding reactions by the prosumers and are therefore a useful functionality.

Summary: The analysis of the bidding phases reveals that the overall bidding activity of all participants is relatively low. While prosumers seem to be slightly more active than consumers, none of them adjusts bids daily or weekly. In addition, we observe that participants become more inactive over time, which needs to be taken into account when designing corresponding systems. The participants mainly stated a lack of time, savings potential, and the market complexity as reasons for their inactivity. Regular reports have been shown to somewhat stimulate participant activity. However, this seems not to be caused by any specific information or incentives contained in the reports but rather by the report itself serving as a reminder. In the interviews, participants did not highlight specifically provided information from the reports but stated that they generally use them to monitor their overall individual performance and for cost control. 


\subsection{Evaluation of consumption behavior - response to price signals}

As described in Chapter 1 and 2, the literature suggests that price signals incentivize participants to shift their consumption into periods with lower prices (in this case, with higher local supply) [49]. In our final analysis, we therefore investigate whether participants respond to price signals by shifting their consumption to times with lower prices. In this analysis, we do not distinguish between prosumers and consumers. We introduced time-varying PV market prices in the trading phases $\mathrm{F}$ and G. Each day in trading phase F included a low priced window between 10 a.m. and 2 p.m. to incentivize participants to shift consumption into the period during which PV generation is usually highest. Participants can shift their consumption, for example, by starting the dishwasher later in the day. The corresponding first hypothesis of this analysis is that participants move parts of their daily consumption into the low priced period (H3.1). In trading phase G, we select the day with the most sunshine hours between two reports based on the weather forecast and decrease the PV market price on that day for the whole day. Each day with a low PV market price is announced in the report before. The second hypothesis is that participants shift their consumption into the low priced day (H3.2). The last part of this analysis then investigates whether consumers change their consumption behavior when they become prosumers. In the interviews, the prosumers stated that they had changed their consumption behavior since the installation of the PV system. According to the interview statements, they increased their consumption during the daytime hours. Therefore, we compare the prosumers' consumption behavior with the consumption values from the previous year, when they were still consumers. We hypothesize that the prosumers have an increased consumption share during daylight hours compared to their consumption from the previous year as consumers (H3.3).

In contrast to the previous preference and report analysis, identifying changes in consumption behavior is a more difficult task. On the one hand, external effects such as weather or events, the start of school vacations, or public holidays can cause consumption behavior to change significantly from one day to the next. On the other hand, weeks from different months cannot be easily compared either, due to temperature or day length changes over the year. For this reason, we establish two benchmarks for each participant. The first benchmark is the week before the 
start of each trading phase. By selecting the benchmarks close to the respective observation period, we minimize misjudgments due to, e.g. seasonal fluctuations. Since this single week may not represent the participants' behavior fully, we establish the second benchmark. This benchmark also represents a week, but each weekday is the average of the four same weekdays from the previous month.

Trading Phase F: Trading phase F consists of four weeks and three days. Each day in this trading phase has a low priced period (10 a.m.- 2 p.m.) in the PV market. In this period, the PV market price is fixed at 10.0 EURct/kWh. Outside the period, it is raised to 20.0 EURct/kWh. We compare each day $i$ with its respective weekday $m$ from the benchmark. For this, we calculate the relative consumption share during the low priced period of each day $d_{i}$. Then we derive the difference between this share and the relative consumption share of the respective benchmark weekday $b_{m}$, to see if participants increased or decreased their consumption in the low priced period. In the last step, we calculate the average deviation $\overline{x_{F}}$ of all days $n$ in trading phase $F$. The formula displays the calculation: $\overline{x_{F}}=\frac{1}{n} \sum_{i=1}^{n}\left(d_{i}-b_{m}\right)$. Is the average value $\overline{x_{F}}$ negative, the consumer reduced her consumption in the low priced period and vice versa increased it if the average value is positive. Table 4 displays each participant's average deviation of all days in trading phase F.

The analysis of both benchmarks for phase $\mathrm{F}$ reveals a positive consumption shift for most participants. Regarding benchmark 1, two participants seem to shift a significant share of their consumption into the low priced period. Participants 6 and 2 have the highest average shift into the low priced period with $7.69 \%$ and $4.66 \%$. Besides these two, participants $1,3,4,7,8$, and 9 show only a small positive shift on average (under $2 \%$ ) towards the low priced periods. In contrast, we observe the opposite effect for participants 5,10 , and 11 . They shift their consumption outside the low priced period and show on average a substantial negative deviation of $-3.41 \%$, $-5.49 \%$, and $-4.84 \%$, respectively. Therefore, the first benchmark analysis seems to suggest that at least two participants directly react to the price signals and shift parts of their consumption, but three participants behave contrarily by decreasing consumption in the low priced period. Benchmark 2 supports these observations. Participants 5, 10, and 11 remain with a negative shift but less pronounced. Par- 
ticipants 2 and 6 show the highest positive consumption shifts. From the remaining participant group with shifts below $2 \%$, all values remain roughly in the same range. Participants 3 and 8 show a small negative shift regarding benchmark 2. In general, the observed shifts become smaller. Therefore, the analysis cannot confirm that participants react to low price incentives and that they shift their consumption within the day. Although many participants show a positive shift, these seem to be rather coincidental results, which is confirmed in the interviews. Similarly, we assume that the negative consumption shifts were unintentional, which is also confirmed by interview statements. Participant 5 stated that he tried to shift his consumption but indicated that this effect did not last long. Overall, we cannot confirm the hypothesis that price signals can incentivize a consumption shift within a day (H3.1).

Trading Phase G: Through trading phase G, we investigate whether low priced days incentivize participants to shift their consumption into these days. There were eight low priced days in total in this phase. Different from the analysis of trading period $\mathrm{F}$, we compare the absolute consumption of each day with the corresponding weekday of each benchmark. We check whether the consumption on the low priced day is higher than on the benchmark weekday and whether the days previous to the low priced day are lower than the respective benchmark day. If both conditions are fulfilled, this is an indication of a possible consumption shift. With this approach, we intend to control whether the day with increased consumption results from a consumption shift or a day within an overall higher consumption week. Table 2 displays the analysis of trading phase $\mathrm{G}$ with both benchmarks. The first column shows the average consumption change of all eight low priced days. The second column indicates whether a consumption shift might be assumed. The analysis of both benchmarks provides a clear picture. In contrast to trading phase F, trading phase $G$ does not show any apparent price signal effects. There are participants who have a higher average consumption on single low priced days, however, the majority show on average a decreased consumption on these days. Participant 9 is the single outlier with increased average consumption. However, this participant shows only a consumption shift in two of the eight days, indicating that he does not shift his consumption in response to the price signal. Therefore, we assume this 
result is random and does not indicate an intended consumption shift. Overall, we conclude that low price announcements seem not to cause consumption shifts between days and reject the second hypothesis of this analysis (H3.2). The interview responses confirm this result. For example, participant 11 states that he noticed the announcement and reports, but they did not result in any behavioral changes.

\begin{tabular}{|c|c|c|c|c|c|c|}
\hline \multirow{2}{*}{ Participant } & F - Benchmark 1 & F - Benchmark 2 & \multicolumn{2}{|c|}{ G - Benchmark 1 } & \multicolumn{2}{|c|}{ G - Benchmark 2 } \\
\cline { 2 - 7 } & $\begin{array}{c}\text { Average } \\
\text { Consumption Shift }\end{array}$ & $\begin{array}{c}\text { Average } \\
\text { Consumption Shift }\end{array}$ & $\begin{array}{c}\text { Average } \\
\text { Consumption Shift }\end{array}$ & $\begin{array}{c}\text { Number } \\
\text { of Days }\end{array}$ & $\begin{array}{c}\text { Average } \\
\text { Consumption Shift }\end{array}$ & $\begin{array}{c}\text { Number } \\
\text { of Days }\end{array}$ \\
\hline 1 & $1.89 \%$ & $0.63 \%$ & $-7.65 \%$ & 1 & $-12.66 \%$ & 0 \\
\hline 2 & $4.66 \%$ & $3.21 \%$ & $-28.23 \%$ & 0 & $-14.95 \%$ & 0 \\
\hline 3 & $0.77 \%$ & $-0.29 \%$ & $-9.25 \%$ & 1 & $-29.6 \%$ & 1 \\
\hline 4 & $1.69 \%$ & $0.05 \%$ & -48.68 & 0 & $-45.21 \%$ & 0 \\
\hline 5 & $-3.41 \%$ & $-1.07 \%$ & $-2.59 \%$ & 3 & $-4.05 \%$ & 0 \\
\hline 6 & $7.69 \%$ & $3.08 \%$ & $-18.17 \%$ & 0 & $-27.74 \%$ & 1 \\
\hline 7 & $1.90 \%$ & $3.00 \%$ & $-5.53 \%$ & 1 & $-7,75 \%$ & 1 \\
\hline 8 & $1.73 \%$ & $-0.81 \%$ & $-6.3 \%$ & 2 & $-30.81 \%$ & 0 \\
\hline 9 & $0.40 \%$ & $0.80 \%$ & $22.44 \%$ & 2 & $28.71 \%$ & 2 \\
\hline 10 & $-5.49 \%$ & $-1.09 \%$ & $-19.82 \%$ & 1 & $-12.81 \%$ & 1 \\
\hline 11 & $-4.84 \%$ & $-1.99 \%$ & $-6.26 \%$ & 0 & $-16.76 \%$ & 2 \\
\hline
\end{tabular}

Table 2 Participants' Consumption Shift Analysis

Prosumers Role Change: Finally, we evaluate whether consumers change their power consumption patterns as they become prosumers. Based on the prosumer interview statements, the hypothesis (H3.3) is that prosumers have increased their consumption share during the daylight hours compared to their consumption behavior as consumers in the previous year. With this consumption shift towards the daylight hours, they can consume more of their self-generated energy from the PV panels. For the analysis, two months (May \& June) from the project phase are compared to the identical months from the previous year. Access to the previous year's data is possible because consumption was recorded before the project's official start. During this time, the three prosumers had not yet installed their own PV systems. An average week is created from each of the two months as consumers and prosumers. For each day, the consumption share during daylight hours is determined. Regarding the available daylight in both months, we consider the period from 9 a.m. to 6 p.m. as daylight time to ensure PV power plants generate sufficient power. Table 3 shows the average consumption share during this time as consumers and prosumers. The proportion of consumption during daylight time reveals that, contrary to the prosumers' statements and impressions, the participants slightly reduced their consumption in the relevant time period. Participant 5 has almost 
not changed consumption (-0.39\%). Participants 7 and 9 show a higher reduction in consumption during the daylight time of $-4.12 \%$ and $-6.48 \%$, respectively. The individual analysis of the weekdays does not show a clear picture either. Therefore, we have to conclude that the prosumers in our project did not significantly change their consumption behavior towards the consumption of more renewable generation when transforming from a consumer to a prosumer. We reject the third hypothesis (H3.3). Additionally, it shows that although the participants consciously tried to move their consumption into the times of the day with PV generation and actually reported this behavior change, the effect does not show in the data and is covered by everyday necessities and habitual behavior, as participant 5 states in the interview.

\begin{tabular}{|c|c|c|c|}
\hline Participant & Consumer Consumption Share & Prosumer Consumption Share & Difference \\
\hline 5 & $53.94 \%$ & $53.55 \%$ & $-0.39 \%$ \\
\hline 7 & $56.51 \%$ & $52.39 \%$ & $-4.12 \%$ \\
\hline 9 & $59.83 \%$ & $53.35 \%$ & $-6.48 \%$ \\
\hline
\end{tabular}

Table 3 Prosumers' Consumption Share Change

Summary: The analysis of the participants' consumption behavior in response to different price signals is surprising from an economic perspective. In trading phase F, individual participants seem to have increased and thus shifted their consumption share during the announced low priced phase. However, these effects are small, are not observed for all participants and only apply to a subgroup. This result suggests that targeted, individual price signals are unlikely to lead to direct consumption shift responses. In the analysis of trading phase $\mathrm{G}$, we investigate whether participants are willing to shift their consumption between different days to low priced days. The analysis results show that participants do not systematically shift their consumption into these low priced days. Therefore, it can be assumed that consumers are not willing or are not able to shift consumption across several days. Finally, the last analysis reveals that consumers who become prosumers do not change their consumption behavior fundamentally. Although the participants state in the interviews that they pay more attention to trying to consume more during hours with possible self-consumption from PV generation, these effects cannot be validated in the data analysis. It can therefore be concluded that the effects result- 
ing from conscious behavioral changes caused by prices or self-generation are very small or non-existent.

\section{Discussion}

We provide first insights into long-term participant behavior within a CEC and compare the observed behavior with assumptions from the literature. For the discussion, a summary of the results is presented in Table 4 .

\begin{tabular}{|c|c|c|c|}
\hline Analyses & Hypotheses & Description & Results \\
\hline \multirow[t]{2}{*}{1} & $\mathrm{H} 1.1$ & $\begin{array}{l}\text { Different preference } \\
\text { for local sources }\end{array}$ & $\begin{array}{l}\text { Converging trend for both sources over time and different between } \\
\text { prosumers and consumers. }\end{array}$ \\
\hline & $\mathrm{H} 1.2$ & $\begin{array}{l}\text { Willingness to } \\
\text { pay premium prices }\end{array}$ & Initial willingness to pay premium prices is high but diminishes fast. \\
\hline \multirow[t]{2}{*}{2} & $\mathrm{H} 2.1$ & $\begin{array}{l}\text { Regular interaction } \\
\text { with the platform }\end{array}$ & $\begin{array}{l}\text { Overall, participants show a low bidding activity. } \\
\text { It is stated that this is caused by a lack of time and market complexity. } \\
\text { Participants monitor their behavior regularly } \\
\text { but show less interest in adjusting their bidding strategy. }\end{array}$ \\
\hline & $\mathrm{H} 2.2$ & Report Information & $\begin{array}{l}\text { Participants do not react to specific information or } \\
\text { price changes from reports by adjusting their bidding strategy. } \\
\text { Regular reports foster bidding activity and } \\
\text { participants perceive them as a useful tool. }\end{array}$ \\
\hline \multirow{3}{*}{3} & $\mathrm{H} 3.1$ & Intra Day & Insignificant consumption shifts into low-price period within a day. \\
\hline & $\mathrm{H} 3.2$ & Between Day & No observable effect. \\
\hline & H3.3 & Prosumer Change & $\begin{array}{l}\text { Perceived behavioral change by the prosumers cannot be } \\
\text { identified in the consumption data. }\end{array}$ \\
\hline
\end{tabular}

Table 4 Result Overview

In the first analysis, we observe that the participants in the project have different preferences for local energy sources and are initially willing to pay premium prices for local PV energy. However, participants reduce their willingness to pay throughout the project. This finding contrasts with studies stating that consumers are willing to pay premium prices for local renewable electricity (e.g.,[45]). This is an important finding, as the initial observations in the project seemed to confirm this assumption. However, we were able to show that this effect does not persist over the period of one year. The long duration of our study is an advantage regarding that question over other studies on the same subject. We explain this negative trend by the need for repeated interactions on the market, which leads the participants to abandon their intentions to pay high prices for local sources and act more economically [54]. It affects the long-term effectiveness of CECs and lowers investment incentives, and it increases the prosumers' investment uncertainty [56]. Operators of CECs need to examine the extent to which participants are willing to pay premium prices more closely in advance and whether this would persist. Alternatively, fixed sales prices could be established abandoning the idea of a market mechanism. An 
open question is whether the initially high bid prices and their reduction can be observed repeatedly in other projects and whether the market mechanism might be the cause for this. In addition, alternative solutions or countermeasures should be further analyzed to prevent the long-term abandoning of premium prices.

Our second analysis shows that the recorded bidding activity is rather low and heterogeneously distributed across the participants. It appears that although participants showed an initial willingness to engage with the system, this declines over time. This result is comparable with the reported activity from the study by [23]. They indicate that some participants show regular activity and others become inactive quickly. In the interviews, participants mentioned several reasons for the decreasing activity (e.g., available time or the overall market mechanism complexity). The most limiting factors for the participants are time resources they are willing to allocate to deal with the system. One participant stated that he had no need to participate actively and only tracked his own data. Other participants said they had less time than expected for the project and then simply forgot about it. Also, participants reported a high market mechanism complexity and that the market results were unclear in many cases. These circumstances resulted in uncertainty, inhibiting some participants from actively participating in the bidding process. This is a very important finding because many different market mechanisms, some of which with a high complexity, are developed and studied in the literature [41]. However, most participants seem to favor a stable mechanism with simple rules and less dynamic pricing. The results show that an easy-to-use system with low complexity is paramount for the success on CECs. In addition, participants state and their behavior shows that regular reminders, like reports, can foster activity and improve the participants' engagement. However, we could not identify specific information or price signals, which trigger activity. Therefore, regular reports may constitute helpful means to foster overall activity and engagement of community participants. However, the main challenge for future CECs will be its participants' activation and regular interaction.

In our final analysis, we evaluate how price signals can incentivize consumption shifts. However, we cannot confirm a reaction to the price signals sent in the trading phases $\mathrm{F}$ and $\mathrm{G}$. It becomes evident that consumption shifts within a day rarely 
occur and the shifted amounts are small. Participants do not integrate shifts during the day within their daily routine. Since the incentive effect for load shifting is listed in the literature as an important advantage [13, 23], further research is needed, especially in this area. Consumption shifts between days cannot be observed at all. The goal must be to find ways to use the local price signals to incentivize consumption shifts of the participants, possibly through the usage of automated systems. Intelligent control systems managing large consumers such as electric vehicles, storage devices, or heat pumps might have greater potential. Simply announcing periods of low prices is not sufficient, and the manual reactions of consumers appear ineffective. In addition, despite statements of behavioral change by the prosumers, we cannot observe any change in consumer behavior when consumers become prosumers. It appears that prosumers overestimate the impact of behavioral adjustments on their consumption behavior.

Even though we are confident that our results will inspire future researchers and strengthen the research strand of CECs, our study is subject to several limitations. First, the number of observed participants in this study is limited. Eleven participants represent a rather small sample, meaning that statistically significant effects cannot be deducted. To this end, we conducted semi-structured interviews with all participants to complement the quantitative analysis, to provide further insights, and to explain the findings in greater detail. Furthermore, we assume a certain degree of self-selection bias as participants were recruited through a local event, and the participation was voluntary. Participants show environmental awareness in the interviews and are interested in green energy. For this reason, it is not clear whether the results also apply to communities, in which other values and interests are represented. Given this limitation, it is particularly interesting that the willingness to pay premiums for local green energy did not persist.

In addition, we only record bid changes and not logins to the user application in this project. Therefore, our statements about the inactivity are based on the bid submission. It cannot be ruled out that participants were more active than indicated by the data. For example, participants can check their individual consumption data or market prices without making any bid changes. Participants stated they used the reports and application regularly to check their individual load values. Therefore, 
the real activity could be higher than assumed but cannot be determined exactly within this study. Nevertheless, it has to be noted that such activity does not contribute to the balancing advantages of CECs if the consumption behaviour is not adjusted.

\section{Conclusion}

Our research yields the first longitudinal insights on participant behavior in CECs with a trading platform. In this study, we conducted a long-term field experiment with eleven participants, of which three are prosumers and eight are consumers. We conduct three analyses, which focus on different assumptions of CECs in the literature. Our analyses evaluate the participants' preferences and willingness to pay premium prices for local energy sources, their activity on the CEC platform and behavioural responses to different provided information. We investigate the effects of different price signals on the participants' consumption behavior and how consumers change it when they become prosumers. We use a mixed-method approach combining quantitative data recorded in the project with semi-structured interviews with the participants after the project. We observe that participants differentiate between local energy sources and show an initial high willingness to pay (premium prices) for local PV power. However, this willingness diminishes fast, and nearly all participants' bid submissions show a negative trend. Furthermore, participants become more inactive throughout the project duration due to different reasons. The most prominently stated reason is a lack of time and overwhelming market complexity. However, regular reports and reminders support the participants in interacting with the community and are perceived as helpful. Regarding price signals, participants show no effective load shifting within or between days. Also, contrary to self-assessment, consumers show no behavioral consumption change when they become prosumers.

Our results show that literature assumptions on user behavior within CECs need to be tested more closely in practice and that the complexity of the platform needs to be reduced in the practical CEC implementation. At the same time, there is a need for additional decision support systems that allow participants to easily and regularly become active on the platform. Similarly, there is a need for better integration of automated systems that take over consumption shifts in an automated 
way for the participants, as they are unwilling or unable to react themselves. Overall,

it can be seen that there is still a great need for research to transfer CECs into practice, while preserving the expected benefits.

\section{Funding}

The research of Bent Richter is supported by the German Research Foundation (DFG) as part of the Research

Training Group GRK 2153: Energy Status Data - Informatics Methods for its Collection, Analysis and Exploitation.

\section{Abbreviations}

CEC - Citizen Energy Community

CHP - Combined Power and Heat

EU - European Union

LAMP - Landau Microgrid Project

LEM - Local Energy Market

PV - Photovoltaics

\section{Availability of data and materials}

The datasets analyzed in this study are not publicly available because the recorded load data is not anonymized.

However, the data are available from the corresponding author on reasonable request.

\section{Ethics approval and consent to participate}

Consent of participants was obtained with relevant assurance of research ethics compliance.

\section{Competing interests}

The authors declare that they have no known competing financial interests or personal relationships that could have appeared to influence the work reported in this paper.

\section{Consent for publication}

Data were collected pseudonymous and the manuscript does not include identifiable details, images, or videos relating to an individual person.

\section{Authors' contributions}

B.R. Conceptualization, Methodology, Visualization, Analysis, Implementation, Data curation, Writing - original draft. P.S Conceptualization, Methodology, Review \& editing, Supervision. C.W. Supervision, Resources.

\section{Author details}

Institute of Information Systems and Marketing, Karlsruhe Institute of Technology (KIT), Karlsruhe, Germany.

\section{References}

1. Di Silvestre, M.L., Favuzza, S., Riva Sanseverino, E., Zizzo, G.: How Decarbonization, Digitalization and Decentralization are changing key power infrastructures. Renewable and Sustainable Energy Reviews 93, 483-498 (2018). doi:10.1016/j.rser.2018.05.068. Accessed 2021-05-27

2. European Commission: Final Report of the High-Level Panel of the European Decarbonisation Pathways Initiative. Publications Office of the European Union, LU (2018).

https://op.europa.eu/en/publication-detail/-/publication/226dea40-04d3-11e9-adde-01aa75ed71a1 Accessed 2021-11-29

3. Knoefel, J., Sagebiel, J., Yildiz, o., Müller, J.R., Rommel, J.: A consumer perspective on corporate governance in the energy transition: Evidence from a Discrete Choice Experiment in Germany. Energy Economics 75 440-448 (2018). doi:10.1016/j.eneco.2018.08.025. Accessed 2021-11-29

4. REN21: Renewables 2014 Global Status Report. Technical report, REN21 Secretariat, c/o UN Environment, Paris (2014). https:

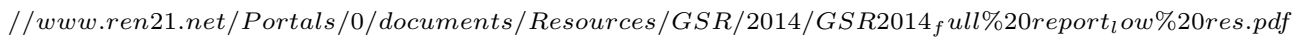
Accessed 2021-11-29 
5. Alanne, K., Saari, A.: Distributed energy generation and sustainable development. Renewable and Sustainable Energy Reviews 10(6), 539-558 (2006). doi:10.1016/j.rser.2004.11.004. Accessed 2020-11-14

6. Press, M., Arnould, E.J.: Constraints on Sustainable Energy Consumption: Market System and Public Policy Challenges and Opportunities. Journal of Public Policy \& Marketing 28(1), 102-113 (2009). doi:10.1509/jppm.28.1.102. Publisher: SAGE Publications Inc. Accessed 2021-11-29

7. Muehlenhoff, J.: Trustworthy Green Electricity Tariffs. The European Consumer Organisation (2016). https : //www.beuc.eu/publications/beuc $-x-2016-002_{j}$ mu $_{t}$ rustworthy reen $_{e}$ lectricity $_{t}$ arif fs.pdf Accessed 2020-11-12

8. Lennon, B., Dunphy, N.P., Sanvicente, E.: Community acceptability and the energy transition: a citizens' perspective. Energy, Sustainability and Society 9(1), 35 (2019). doi:10.1186/s13705-019-0218-z. Accessed 2022-01-22

9. Meister, T., Schmid, B., Seidl, I., Klagge, B.: How municipalities support energy cooperatives: survey results from Germany and Switzerland. Energy, Sustainability and Society 10(1), 18 (2020). doi:10.1186/s13705-020-00248-3. Accessed 2022-01-22

10. Hisschemöller, M., Sioziou, I.: Boundary organisations for resource mobilisation: enhancing citizens' involvement in the Dutch energy transition. Environmental Politics 22(5), 792-810 (2013). doi:10.1080/09644016.2013.775724. Accessed 2021-03-17

11. Bauwens, T., Gotchev, B., Holstenkamp, L.: What drives the development of community energy in Europe? The case of wind power cooperatives. Energy Research \& Social Science 13, 136-147 (2016). doi:10.1016/j.erss.2015.12.016. Accessed 2021-11-29

12. European Parliament: Directive (EU) 2019/944 of the European Parliament and of the Council of 5 June 2019 on common rules for the internal market for electricity and amending Directive 2012/27/EU. Code Number: 158 (2019). http://data.europa.eu/eli/dir/2019/944/oj/eng Accessed 2021-05-16

13. Koirala, B.P., Koliou, E., Friege, J., Hakvoort, R.A., Herder, P.M.: Energetic communities for community energy: A review of key issues and trends shaping integrated community energy systems. Renewable and Sustainable Energy Reviews 56, 722-744 (2016). doi:10.1016/j.rser.2015.11.080. Accessed 2020-11-15

14. Wuebben, D., Romero-Luis, J., Gertrudix, M.: Citizen Science and Citizen Energy Communities: A Systematic Review and Potential Alliances for SDGs. Sustainability 12(23), 10096 (2020). doi:10.3390/su122310096. Accessed 2021-03-17

15. Sousa, T., Soares, T., Pinson, P., Moret, F., Baroche, T., Sorin, E.: Peer-to-peer and community-based markets: A comprehensive review. Renewable and Sustainable Energy Reviews 104, 367-378 (2019). doi:10.1016/j.rser.2019.01.036. Accessed 2020-11-13

16. Bremdal, B.A., Olivella-Rosell, P., Rajasekharan, J., Ilieva, I.: Creating a local energy market. CIRED - Open Access Proceedings Journal 2017(1), 2649-2652 (2017). doi:10.1049/oap-cired.2017.0730. Accessed 2020-11-15

17. Mengelkamp, E., Gärttner, J., Rock, K., Kessler, S., Orsini, L., Weinhardt, C.: Designing microgrid energy markets. Applied Energy 210, 870-880 (2018). doi:10.1016/j.apenergy.2017.06.054. Accessed 2020-11-14

18. Ilic, D., Da Silva, P.G., Karnouskos, S., Griesemer, M.: An energy market for trading electricity in smart grid neighbourhoods. In: 2012 6th IEEE International Conference on Digital Ecosystems and Technologies (DEST), pp. 1-6. IEEE, Campione d'Italia, Italy (2012). doi:10.1109/DEST.2012.6227918. http://ieeexplore.ieee.org/document/6227918/ Accessed 2021-08-29

19. Stadler, M., Cardoso, G., Mashayekh, S., Forget, T., DeForest, N., Agarwal, A., Schönbein, A.: Value streams in microgrids: A literature review. Applied Energy 162, 980-989 (2016). doi:10.1016/j.apenergy.2015.10.081. Accessed 2021-06-03

20. Parag, Y., Sovacool, B.K.: Electricity market design for the prosumer era. Nature Energy 1(4), 1-6 (2016). doi:10.1038/nenergy.2016.32. Number: 4 Publisher: Nature Publishing Group. Accessed 2021-05-27

21. Brounen, D., Kok, N., Quigley, J.M.: Energy literacy, awareness, and conservation behavior of residential households. Energy Economics 38, 42-50 (2013). doi:10.1016/j.eneco.2013.02.008. Accessed 2021-04-24

22. Pouttu, A., Haapola, J., Ahokangas, P., Xu, Y., Kopsakangas-Savolainen, M., Porras, E., Matamoros, J., Kalalas, C., Alonso-Zarate, J., Gallego, F.D., Martin, J.M., Deconinck, G., Almasalma, H., Clayes, S., Wu, J., Meng Cheng, Li, F., Zhipeng Zhang, Rivas, D., Casado, S.: P2P model for distributed energy trading, grid 
control and ICT for local smart grids. In: 2017 European Conference on Networks and Communications (EuCNC), pp. 1-6. IEEE, Oulu, Finland (2017). doi:10.1109/EuCNC.2017.7980652.

http://ieeexplore.iee.org/document/7980652/ Accessed 2021-11-23

23. Ableitner, L., Tiefenbeck, V., Meeuw, A., Wörner, A., Fleisch, E., Wortmann, F.: User behavior in a real-world peer-to-peer electricity market. Applied Energy 270, 115061 (2020). doi:10.1016/j.apenergy.2020.115061. Accessed 2020-06-07

24. Oteman, M., Wiering, M., Helderman, J.-K.: The institutional space of community initiatives for renewable energy: a comparative case study of the Netherlands, Germany and Denmark. Energy, Sustainability and Society 4(1), 11 (2014). doi:10.1186/2192-0567-4-11. Accessed 2022-01-22

25. Orozco, C., Lilla, S., Borghetti, A., Napolitano, F., Tossani, F.: An ADMM Approach for Day-Ahead Scheduling of a Local Energy Community. In: 2019 IEEE Milan PowerTech, pp. 1-6. IEEE, Milan, Italy (2019) doi:10.1109/PTC.2019.8810578. https://ieeexplore.ieee.org/document/8810578/ Accessed 2021-11-20

26. Soeiro, S., Ferreira Dias, M.: Renewable energy community and the European energy market: main motivations. Heliyon 6(7), 04511 (2020). doi:10.1016/j.heliyon.2020.e04511. Accessed 2021-11-20

27. Romero-Rubio, C., de Andrés Díaz, J.R.: Sustainable energy communities: a study contrasting Spain and Germany. Energy Policy 85, 397-409 (2015). doi:10.1016/j.enpol.2015.06.012. Accessed 2021-05-31

28. Capellán-Pérez, I., Campos-Celador, A., Terés-Zubiaga, J.: Renewable Energy Cooperatives as an instrument towards the energy transition in Spain. Energy Policy 123, 215-229 (2018). doi:10.1016/j.enpol.2018.08.064. Accessed 2021-11-20

29. REScoop: REScoop (2021). https://www.rescoop.eu/ Accessed 2021-11-20

30. Warneryd, M., Håkansson, M., Karltorp, K.: Unpacking the complexity of community microgrids: A review of institutions' roles for development of microgrids. Renewable and Sustainable Energy Reviews 121, 109690 (2020). doi:10.1016/j.rser.2019.109690. Accessed 2021-11-20

31. Walker, G., Devine-Wright, P.: Community renewable energy: What should it mean? Energy Policy 36(2), 497-500 (2008). doi:10.1016/j.enpol.2007.10.019. Accessed 2021-05-31

32. Walker, G.: What are the barriers and incentives for community-owned means of energy production and use? Energy Policy 36(12), 4401-4405 (2008). doi:10.1016/j.enpol.2008.09.032. Accessed 2021-11-20

33. Cornélusse, B., Savelli, I., Paoletti, S., Giannitrapani, A., Vicino, A.: A community microgrid architecture with an internal local market. Applied Energy 242, 547-560 (2019). doi:10.1016/j.apenergy.2019.03.109. Accessed 2021-11-20

34. Gui, E.M., Diesendorf, M., MacGill, I.: Distributed energy infrastructure paradigm: Community microgrids in a new institutional economics context. Renewable and Sustainable Energy Reviews 72, 1355-1365 (2017). doi:10.1016/j.rser.2016.10.047. Accessed 2021-11-20

35. Perger, T., Wachter, L., Fleischhacker, A., Auer, H.: PV sharing in local communities: Peer-to-peer trading under consideration of the prosumers' willingness-to-pay. Sustainable Cities and Society 66, 102634 (2021) doi:10.1016/j.scs.2020.102634. Accessed 2021-11-20

36. Kunze, C., Becker, S.: Collective ownership in renewable energy and opportunities for sustainable degrowth. Sustainability Science 10(3), 425-437 (2015). doi:10.1007/s11625-015-0301-0. Accessed 2021-03-17

37. Gui, E.M., MacGill, I.: Typology of future clean energy communities: An exploratory structure, opportunities, and challenges. Energy Research \& Social Science 35, 94-107 (2018). doi:10.1016/j.erss.2017.10.019. Accessed 2021-03-17

38. Schram, W., Louwen, A., Lampropoulos, I., van Sark, W.: Comparison of the Greenhouse Gas Emission Reduction Potential of Energy Communities. Energies 12(23), 4440 (2019). doi:10.3390/en12234440. Number: 23 Publisher: Multidisciplinary Digital Publishing Institute. Accessed 2021-05-26

39. Zwickl-Bernhard, S., Auer, H.: Citizen Participation in Low-Carbon Energy Systems: Energy Communities and Its Impact on the Electricity Demand on Neighborhood and National Level. Energies 14(2), 305 (2021). doi:10.3390/en14020305. Number: 2 Publisher: Multidisciplinary Digital Publishing Institute. Accessed 2021-05-25

40. Caramizaru, A., Uihlein, A.: Energy Communities: an Overview of Energy and Social Innovation. Publications Office of the European Union, ??? (2020). https://publications.jrc.ec.europa.eu/repository/handle/JRC119433

41. Mengelkamp, E., Diesing, J., Weinhardt, C.: Tracing Local Energy Markets: A Literature Review. it - 
Information Technology 61(2-3), 101-110 (2019). doi:10.1515/itit-2019-0016. Publisher: Unpublished. Accessed 2021-03-19

42. Zade, M., Lumpp, S.D., Tzscheutschler, P., Wagner, U.: Satisfying user preferences in community-based local energy markets - Auction-based clearing approaches. Applied Energy 306, 118004 (2022). doi:10.1016/j.apenergy.2021.118004. Accessed 2021-11-23

43. Ma, C., Rogers, A.A., Kragt, M.E., Zhang, F., Polyakov, M., Gibson, F., Chalak, M., Pandit, R., Tapsuwan, S.: Consumers' willingness to pay for renewable energy: A meta-regression analysis. Resource and Energy Economics 42, 93-109 (2015). doi:10.1016/j.reseneeco.2015.07.003. Accessed 2021-05-31

44. Borchers, A.M., Duke, J.M., Parsons, G.R.: Does willingness to pay for green energy differ by source? Energy Policy 35(6), 3327-3334 (2007). doi:10.1016/j.enpol.2006.12.009. Accessed 2021-06-03

45. Mengelkamp, E., Schönland, T., Huber, J., Weinhardt, C.: The value of local electricity - A choice experiment among German residential customers. Energy Policy 130, 294-303 (2019). doi:10.1016/j.enpol.2019.04.008. Accessed 2020-11-13

46. Mengelkamp, E., Staudt, P., Garttner, J., Weinhardt, C.: Trading on local energy markets: A comparison of market designs and bidding strategies. In: 2017 14th International Conference on the European Energy Market (EEM), pp. 1-6 (2017). doi:10.1109/EEM.2017.7981938. ISSN: 2165-4093

47. Chen, T., Su, W.: Local Energy Trading Behavior Modeling With Deep Reinforcement Learning. IEEE Access 6, 62806-62814 (2018). doi:10.1109/ACCESS.2018.2876652. Accessed 2021-11-04

48. Zhang, C., Wu, J., Zhou, Y., Cheng, M., Long, C.: Peer-to-Peer energy trading in a Microgrid. Applied Energy 220, 1-12 (2018). doi:10.1016/j.apenergy.2018.03.010. Accessed 2021-03-19

49. Faruqui, A., Sergici, S., Warner, C.: Arcturus 2.0 : A meta-analysis of time-varying rates for electricity. The Electricity Journal 30(10), 64-72 (2017). doi:10.1016/j.tej.2017.11.003. Accessed 2021-11-25

50. Richter, B., Mengelkamp, E., Weinhardt, C.: Vote for your energy: a market mechanism for local energy markets based on the consumers' preferences. In: 2019 16th International Conference on the European Energy Market (EEM), pp. 1-6. IEEE, Ljubljana, Slovenia (2019). doi:10.1109/EEM.2019.8916544. https://ieeexplore.ieee.org/document/8916544/ Accessed 2020-11-13

51. Richter, B., Golla, A., Welle, K., Staudt, P., Weinhardt, C.: Local energy markets - an IT-architecture design. Energy Informatics 4(S2), 35 (2021). doi:10.1186/s42162-021-00164-6. Accessed 2021-11-08

52. Bhattacherjee, A.: Social Science Research: Principles, Methods, and Practices, (2012). Publisher: Global Text Project

53. Kaiser, R.: Qualitative Experteninterviews: Konzeptionelle Grundlagen und Praktische Durchführung. Springer, ??? (2014)

54. Falk, A., Szech, N.: Morals and Markets. Science 340(6133), 707-711 (2013). doi:10.1126/science.1231566. Accessed 2021-09-26

55. Nisi, V., Nicoletti, D., Nisi, R., Nunes, N.J.: Beyond Eco-feedback: using art and emotional attachment to express energy consumption. In: Proceedings of the 8th ACM Conference on Creativity and Cognition - C\&C '11, p. 381. ACM Press, Atlanta, Georgia, USA (2011). doi:10.1145/2069618.2069706. http://dl.acm.org/citation.cfm?doid=2069618.2069706 Accessed 2022-01-04

56. Morstyn, T., Farrell, N., Darby, S.J., McCulloch, M.D.: Using peer-to-peer energy-trading platforms to incentivize prosumers to form federated power plants. Nature Energy 3(2), 94-101 (2018).

doi:10.1038/s41560-017-0075-y. Number: 2 Publisher: Nature Publishing Group. Accessed 2020-05-25 
Figures

Consumer PV Bid Price Overview

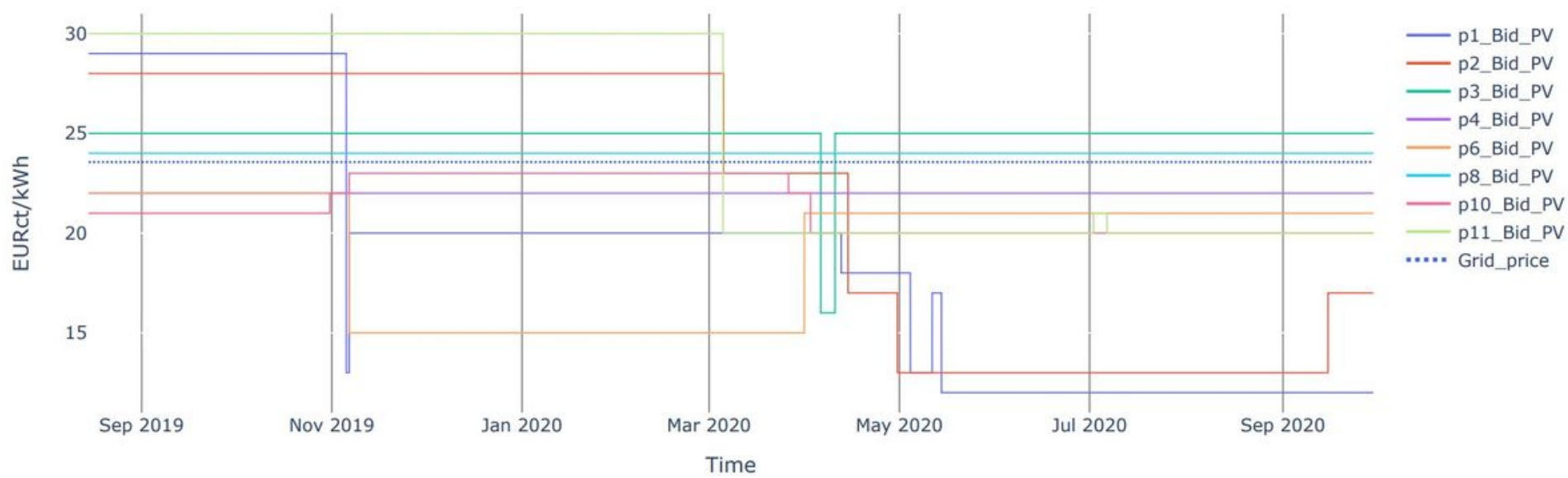

\section{Figure 1}

Consumer PV bid prices throughout project duration

\section{Consumer CHP Bid Price Overview}

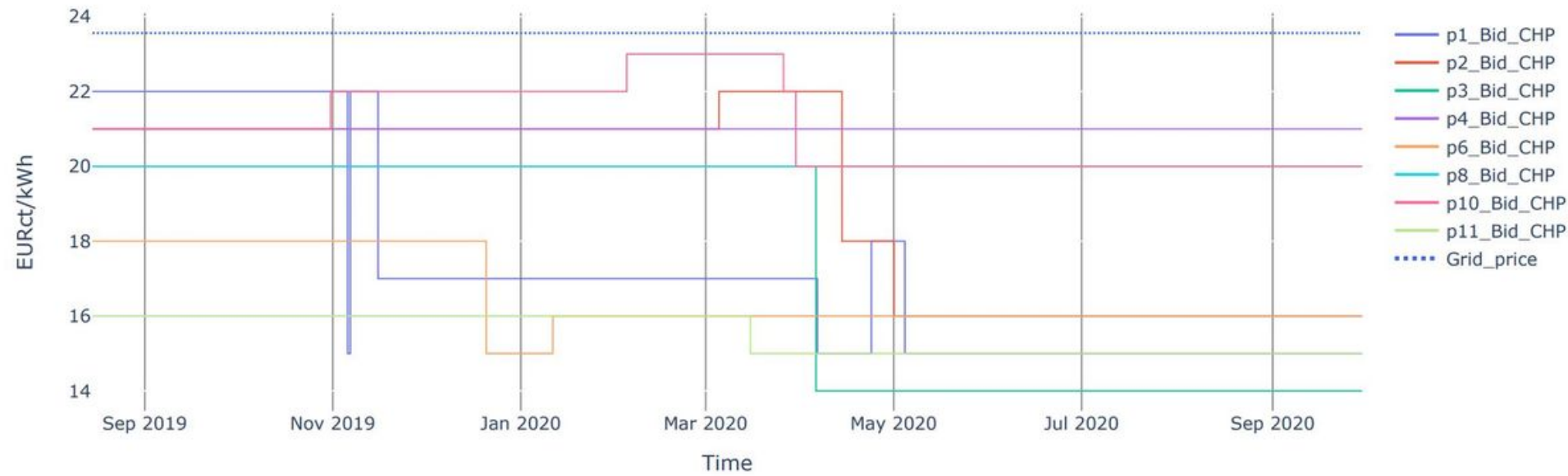

\section{Figure 2}

Consumer $\mathrm{CHP}$ bid prices throughout project duration 
Prosumer Bid Price Overview

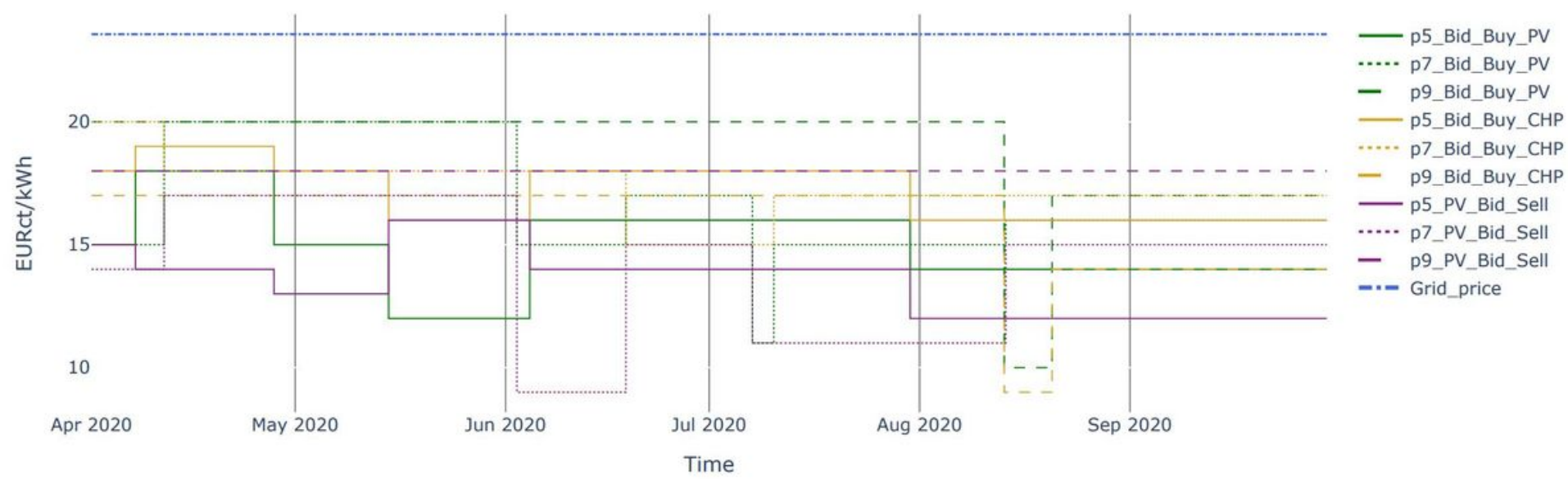

Figure 3

Prosumer bid prices throughout project duration 